understanding of the part science plays in cultural life, including moral and even, perhaps, spiritual issues. In this sense the ideological content of syllabuses will have to be brought under review. Points liko these pose difficult questions for teachers and examiners, but if in their training young scientists are to be treated wholly as specialists they will remain nothing but specißlists when they grow up.

R. WeAtherati

\title{
REPORT OF THE AGRICULTURAL RESEARCH COUNCIL 1963-65
}

\begin{abstract}
T HE Report of the Agricultural Research Council for the years 1963-65 (Cmnd. 2792, H.M. Stationory Office, 8s.) describes tho work of twelve out of the forty. seven institutes and units for which the council is, in effect, responsible; summarizes sorno of the major developments in the two yeurs under review; and, in so doing, demonstrates tho wide range of modern agricultural research. Thus, in soils, work (some of which may be relevant to prablic health) on the persistence of organo-ehlorine insecticides shows that a single dressing of dieldrin has offectively controlled carrot fly, Psila rosae, for nine years, while very low residues of this compound reduced the natural enomios of the cabbage root fly, Erioischia brassicae, and thus aided the survival of this pest. If the placement of fertilizers at depths of up to $2.5 \mathrm{ft}$. can be made practicable, then sub-soil water could be more effectively used by pastures, and irrigation noods reduced.

In crops, the influence of kinins on root growth, gormination, bud growth and loaf-sonescence (which affects the effective photosynthetic area) is noted, while revolutionary possibilitios are opened up by complete chemical control of vegetation which permits 'minimal cultivation' and even brings into question the nceessity for ploughing.

In animals, resoarch on the metabolism of clinical disorders associated with calcium, phosphorus, iron, copper, magnesium, zine and solenium illustrates the biochemical comploxities of intensive animal production, while work at tho Animal Diseases Research Association in Seotland on that elusive disense of shoep, scrapie, oxemplifies the value of multi-discipline researeh. A link
\end{abstract}

between reproduction research in humans and livestock is seen in the uso, on pigs, of a temporary ovulation inhibitor which opens up tho prospect of synchronizex 'batch farrowing' by pig producers.

The Council (which now reports to the Department of Education and Science) is, of course, primarily concorned with scientific and engineering rosoarch. This may explain why there is no mention of the tentative, but potentially very important, link betwoon scientific and farm management research through the croation, by multi-variable experiments, of the muli-dimensional input-output curves so badly neoded for the effective application to farming of modern business mathomatics.

The roport concludes with administrative and financial data. The total spent each year by or on behalf of the Council is about $£ 10$ million in Great Britain. This oxcludes research at official husbandry farms, on farm management, by agricultural economists, by the official veterinary service, by the supporting chemical and ongineering industries and by agricultural scientists at univorsities. Even if this group spent as much as the Agricultural Research Council, the total resoarch expenditure on and in the agricultural industry would only be about 1 per cent of the value of its gross annual sales. In farming in the United Kingdom, productivity per man is increasing at about 7 per cent per annum-one of the highest rates in the national cconomy. What further contribution could agriculture make to national conomic efficiency if rosearch expenditure was doubled? A. N. Duckнaм

\section{ANTIMICROBIAL AGENTS AND CHEMOTHERAPY}

$\mathrm{V}^{\mathrm{s}}$ ARIOUS aspects of antimicrobial agents, infectious diseases, and chemothorapy were discussed during October 17-21, 1965, in the 237 papers and 11 round tables and conferences presented at the fifth Interscionce Conference on Antimicrobial Agonts and ChemotherapyFourth International Congress for Chemotherapy. This moeting was held in Wushington, under the sponsorship of the American Society for Microbiology and the International Society for Chemotherapy, and was organized with the co-operation of the Infectious Diseases Society of America. 1,422 interestod scientists attended this meeting; 228, representing 26 countries, came from outside the United States.

The Congress opened with addresses by Prof. E. B. Chain, Prof. S. A. Waksman, and Prof. J. F. Enders, discussing the past 25 years of antibiotic therapy and prospects for the future. This theme of reviewing the accomplishment of the past and problems of the immediate future was carried further in a round table on "Are Now Antibioties Neoded ?" organized by Prof. M. Fintand. The consensus of the panol membors, including Profs. W. M. M. Kirby, H. F. Dowling, A. C. Todd and L. P. Garrod, and Prof. E. B. Chain, Dr. Y. Chabbert and Dr. C. W. Pettinga, was that new and specialized antibiotics are still needod. There aro many infections which are not adequately treated by tho availablo antimicrobial agents and there is a need for a 'good' antifungal agont, a better anti-Gram-nogativo bacterial agent, and agents to troat a host of 'uncovered diseases' including the viral diseases and those caused by protozoa and othor parasites. Other round tables wore concerned with "Gram-negative Infections", "Antibiotic Assay Mothods", "Bacterial Sonsitivity Testing Methods", and the "Chomothorapy of Venereal Diseasos". In each of these panel discussions, experts from many countries reviewed their findings in the particular subject being discussed, and presented now information on the prospocts for the immediate future. The need for non-toxic and effective antibioties in the treatmont of Gram-negative infections, the fungal infertions, and in venereal disoases was repeatedly emphasized.

Among the topics discussed at the 'informal discussions' were: practical methods for handling information on antibiotics and chemotherapy; the activities of the International Conter for Antibiotic Information (Liège); antibiotic nomenclature; and ecological roles of antibiotics. The following rules were proposed for choosing antibiotic names: (a) an antibiotic's name should be chosen so that, if it is later shown to be a momber of a family, the rootname can be modified to show members of tho related sories. (b) The name should be based on chemical structure, and, except where the structuro is known, the name should be based on the generic class of the producing organism. (c) The name chosen should be euphonious.

A symposium on the chemotherapy of tuberculosis (organized by Dr. G. Brouet, Paris) included discussion of experimental bases of chemotherapy (by Dr. F. Grumbach), therapoutic possibilities with minor antibacterial drugs in infections with Mycobacterium tuberculosis (Prof. 
K. L. Radenbach), and the United States Public Health Service trials of isoniazid prophylaxis. In the latter, Mrs. Shirley Ferebee summarized the experience with trials involving 73,000 participants, and concluded that in the 4-9 years of observation after the prophylaxis year, isoniazid reduced the incidence of tuberculosis by 50 per cent in all trials.

Cancer chemotherapy was the subject of another symposium (convened by Prof. C. Heidelberger). Among the subjects reviewed were the antitumour antibiotics (by Prof. H. Umozawa), immunological approaches to host-tumour interactions (by Dr. M. Feldman), the relationships of pharmacology and cancer chemotherapy (by Dr. D. P. Rall, National Institutes of Health), and the present status of clinical cancer chemotherapy (by Prof. F. J. Ansfield). Of particular interest was Dr. Feldman's presentation of the value of the immunological approach in experimental cancer chemotherapy.

The pharmacology and pharmaco-kinetics of chemotherapeutic agents were discussed in a variety of the contributions. Of noteworthy interest was a discussion of the antibiotic absorption following otic administration as observed by M. J. Weinstein and colleagues (Schering Corporation). (This approach reminded the audience of Shakespeare's treatment of the subject in Hamlet (Act I, scene 5).) The pharmaco-kinetie discussions included experimental models, the logistics of chemotherapy, the pharmaco-kinetic studies using sulphonamides and ABOB, and protein binding studies. The latter subject was treated more fully in a symposium on penetration of drugs into tissues (convened by Prof. W. F. Verwey), where special attention was given to serum protein binding of penicillins and other drugs, the penetration of chemotherapeutic agents into cells, passage of drugs into and out of the central nervous system, and mechanisms of drug transfer across the placenta.

As more is known of the mechanisms of action of various antibiotics, it is possible to use these inhibitory agents as biochemical tools. Prof. J. T. Park led a symposium which disoussed the use of chloramphenicol in the investigation of the synthesis of lysine peptides by enzyme systems, antibiotics as inhibitors of cell wall synthesis, the use of aminoglycoside antibioties in studying the genetic code, and the antifungal antibiotics as agents in observing the physiology of moulds and yeasts.

The first day of the Congress was devoted to a series of papers on problems of infectious disease. These included: a discussion of endotoxin; clinical significance of the occurrence of various Gram-negative organisms ; infections following cardiac surgery; a series of papers on Myeoplasma as infectious agents; and immunization using adenovirus vaccines and parainfluenza virus vaccines. New penicillins were discussed in other clinically oriented discussions, with special emphasis on cephaloridine in therapy of a variety of bacterial infections. The differences in the $\beta$-lactamases hydrolysing penicillins and those splitting cephalosporin $C$ were summarized by Sabath and Abraham, who noted a zine co-factor requirement for the latter, as well as differences in heat stability in these enzymes from Bacillus cereus.

The chemistry of antimicrobial agents was discussed in a symposium (organized by Prof. K. L. Rinehart, University of Tllinois) and in a series of contributed papers. Among the especially noteworthy reports were:

(1) The presentation of the structure of the iron-containing antibiotic, ferrimycin $A_{1}$, and the disclosure that a 'minor change' of an amide group changes this from an antibiotic to a growth factor. (This work was done at the Federal Institute of Technology, Zurich, under the direction of Prof. V. Prelog.)

(2) A study of the structure-activity relationships among the depsipeptide antibiotics (with special reference to valinomycin) was summarized by Academician M. M. Shemyakin (Institute for Chemistry of Natural Products, Moscow), who concluded that there is a parallelism between their anti-fungal activity and their ability selectively to induce active $\mathrm{K}^{+}$transport in mitochondria.

(3) Proof of the structure of the antibiotic verrucarin $A$ was used by Prof. G. A. Sim (University of Illinoiz) to demonstrate the usefulness of X-ray crystallography in determining the structures of antibiotics and other natural products.

(4) The mode of anti-tumour action of the coppercontaining phleomycins, and the new antibiotics, bleomycins, was reported by Prof. H. Umezawa (Institute of Applied Mierobiology, Tokyo) to involve inhibition of DNA synthesis as with pluramycin. On the other hand, the high molecular weight enomycin was found to have a solective action on ascites cells and was more rapidly absorbed by these cells than by normal cells.

(5) A series of antibiotics, the moenomycins, were described by Schmidt-Thome (Hoechst) as having the empirical formula: $\left(\mathrm{C}_{70} \mathrm{H}_{124} \mathrm{~N}_{7} \mathrm{O}_{40} \mathrm{P}\right)_{n}$. Hydrolyses showed the presence of: glucose; glucosamine; quinovosamine; phosphoric acid monoesters; a terpene-like carbon chain; and a chromophore. These antibiotics are active against Gram-positive bacteria. Very slow elimination was noted on subcutaneous administration, and blood levels of moenomycins were demonstrated 47 days after administration. The moenomycins have been widely tested as feed supplements, and were found more useful than the tetracyclines in growth promotion tests with broilers, pigs and calves.

(6) Kasugamycin, an aminoglycoside antibiotic, was originally selected on the basis of antifungal activity against rice blast disease. It was reported by Prof. $\mathrm{H}$. Umezawa and Dr. T. Ichikawa (First National Hospital, Tokyo) to be useful in controlling Pseudomonas infections in clinical trials.

(7) Desdamine, desdamethine and ethesdamine are new antibiotics formed when $S$-methyl cysteine or $S$-ethyl cysteine was added to celesticetin producing fermentations.

(8) Everninomicin $B$ is an antibiotic produced by Micromonospora carbonacea. It is active in vivo against Gram-positive bacteria.

(9) A group of antibiotics called the sugordomycins were deseribed by Berger et al. (Hoffmann-LaRoche) as chemically related to the coumermyeins, and having favourable in vivo potentialities against Gram-positive infections.

(10) Wiley (The Upjohn Company) reported on the identification of a cytotoxic agent $U-20,904$ as cis- $\beta$ acrylamidine.

(11) The structure of alazopeptin was reported by Patterson (Lederle Laboratories) to be L-alanyl-(6-diazo5-oxo)-t-norleucy]-(6-diazo-5-oxo)-L-norleucine.

Most of the papers presented at this Congress will appear in Antimicrobial Agents and Chemotherapy-1965, which will be published in June 1966, by the American Society for Microbiology. The book will be distributed to all registrants at the meeting, and will be available from the headquarters of the Society, 115 Huron View Boulevard, Ann Arbor, Michigan.

Plans for the 1966 Interscience Conference on Antimicrobial Agents and Chemotherapy are already under way. This conference will be sponsored by the American Soeiety for Microbiology and organized with the co-opera. tion of the Infectious Diseases Society of America. The sessions will be held during October 26-28, 1966, in the Sheraton Hotel, Philadelphia. Among the topies which will probably be discussed in symposia and round tables are: identification of antibiotics; chemical modification of antibiotics; adverse reactions to drugs; chemotherapy under immunosuppressive conditions; epidemiology of antibiotic-resistant infections; and non-pharmaceutical uses of antibiotics. Further information on the meeting and abstract forms can be obtained from $\mathrm{Mr}$. R. W. Sarber, executive secretary, American Society for Microbiology, 115 Huron View Boulevard, Ann Arbor, Michigan. 